\title{
Profile of aripiprazole in the treatment of bipolar disorder in children and adolescents
}

This article was published in the following Dove Press journal:

Adolescent Health, Medicine and Therapeutics

27 November 2014

Number of times this article has been viewed

\section{Eiji Kirino ${ }^{1-3}$}

'Department of Psychiatry, Juntendo University School of Medicine, ${ }^{2}$ Department of Psychiatry, Juntendo University Shizuoka Hospital, 3 Juntendo Institute of Mental Health, Shizuoka, Japan
Correspondence: Eiji Kirino Juntendo University Shizuoka Hospital, I 29 Nagaoka Izunokunishi,

Shizuoka, Japan

Tel +8I 55948 3 I I I

$\mathrm{Fax}+8 I 559485088$

Email ekirino@juntendo.ac.jp

\begin{abstract}
Bipolar disorder is a pernicious illness. Compared with the later-onset form, early onset bipolar disorder is associated with worse psychosocial outcomes, and is characterized by rapid cycling and increased risks of substance abuse and suicide attempts. Controlling mood episodes and preventing relapse in this group of pediatric patients requires careful treatment. Here, we review the effectiveness of aripiprazole for bipolar disorder in children and adolescents, with discussion of this drug's unique pharmacological profile and various clinical study outcomes. Aripiprazole acts as a serotonin 5-HT2A receptor antagonist, as well as a partial agonist of the serotonin 5-HT1A and dopamine D2 receptors. It can be safely used in children and adolescents, as it is highly tolerated and shows lower rates of the side effects typically observed with other antipsychotic drugs, including sedation, weight gain, hyperprolactinemia, and extrapyramidal syndrome. The presently reviewed randomized controlled trials (RCTs) and non-RCTs generally reported aripiprazole to be effective and well-tolerated in children and adolescents with bipolar disorder. However, due to the limited number of RCTs, the present conclusions must be evaluated cautiously. Furthermore, aripiprazole cannot yet be considered a preferred treatment for children and adolescents with bipolar disorder, as there is not yet evidence that aripiprazole shows greater efficacy compared to other second-generation antipsychotics. Additional data are needed from future head-to-head comparison studies.
\end{abstract}

Keywords: child, mania, mixed state

\section{Introduction}

Pediatric bipolar disorder is a pernicious illness associated with substantial functional impairment and quality-of-life reductions. ${ }^{1}$ Previously considered rare, pediatric bipolar disorder is now thought to be more common. ${ }^{2}$ However, there remains some controversy regarding the clinical prevalence of bipolar disorders in prepubertal children, and the diagnosis is often misapplied due to a relative paucity of data regarding the heterogeneity of this disorder among children and adolescents. ${ }^{3-5}$ While intense debate continues over the occurrence of nosological onset of bipolar disorder among prepubertal children, it is clear that growing numbers of children and adolescents are requiring mental health services for extreme emotional lability related to aggressive behavior and intense irritability. ${ }^{6}$

The exact prevalence of pediatric bipolar disorder is unknown, but it is estimated that bipolar spectrum conditions may affect $2 \%$ of children and adolescents worldwide, ${ }^{7,8}$ with bipolar disorder possibly affecting 2 million children younger than 13 years of age in the US. ${ }^{9,10}$ It is also reported that at least one-third ${ }^{11}$ or $50 \%-66 \%{ }^{12}$ of adult bipolar disorder cases begin in childhood and adolescence. One large nationally 
representative sample of children and adolescents seen in office-based settings reported a 40-fold increase in bipolar disorder diagnosis rates from 1994 to $2003 .{ }^{10}$ In earlyonset bipolar disorder, the onset of symptoms occurs before 18 years of age. Compared to cases of later-onset bipolar disorder, early-onset cases reportedly have worse psychosocial outcomes, including rapid cycling and increased risks of substance abuse and suicide attempts. ${ }^{9,13-15}$ Patients with early-onset bipolar disorder suffer long-term consequences that substantially impair their ability to perform normal functions of daily life, consequently having devastating impact on their school performance, family relationships, and social interactions. ${ }^{16}$ To control mood episodes and prevent relapse, these pediatric patients require careful treatment. ${ }^{9}$

The current treatment of pediatric bipolar disorder involves a variety of pharmacotherapeutic, psychotherapeutic, psychosocial, and educational interventions. ${ }^{9}$ Increasing recognition of pediatric bipolar disorder brings about an increased demand for validated treatment methods. ${ }^{17}$ For many years, children with bipolar and other disorders have been treated with typical antipsychotics and mood stabilizers. Pharmacotherapeutic options for treating bipolar disorder in children and adolescents now also include several atypical antipsychotics, ${ }^{17}$ with four medications currently approved for this population by the US Food and Drug Administration (FDA): aripiprazole, olanzapine, quetiapine, and risperidone. The emergence of atypical antipsychotics has provided treatments with fewer neurological side effects and greater tolerability. ${ }^{18}$ Furthermore, it is suggested that typical antipsychotic therapy in the pediatric population can induce or worsen depression, ${ }^{19}$ while atypical antipsychotics may prevent or delay depression development among patients with bipolar disorder. ${ }^{20-22}$

In the previously mentioned nationally representative sample, $48 \%$ of the pediatric subjects who were diagnosed with bipolar disorder between 1999 and 2003 were prescribed an antipsychotic agent. ${ }^{10}$ First-line treatment generally includes atypical antipsychotic agents, along with mood stabilizers. ${ }^{23,24}$ However, there are safety concerns regarding long-term use of combined agents in children and adolescents. ${ }^{25}$ Randomized clinical trials (RCTs) demonstrated that risperidone, ${ }^{26}$ quetiapine, ${ }^{27}$ and olanzapine ${ }^{28}$ were significantly superior to placebo; however, increased experience with these drugs revealed drawbacks to these newer medications, including weight gain and other metabolic and endocrine side effects. ${ }^{18}$ The introduction of aripiprazole in the mid-1990s provided another option for child and adolescent psychiatrists as well as for generalists. ${ }^{29}$
Aripiprazole is a partial agonist of dopamine D2 $2^{30}$ that is distinctive from conventional antipsychotics. It shows efficacy and tolerability in multiple psychotic diseases, and review articles have highlighted its reported safety and tolerability in children and adolescents. ${ }^{6,18,31-35}$ The FDA approves aripiprazole for use in bipolar I disorder and schizophrenia treatment. Regarding its use in children and adolescents, aripiprazole is indicated in the US for acute and maintenance treatment of schizophrenia among adolescents (aged 13-17 years). It is also approved for use as a monotherapy or an adjunct to lithium or valproate in the acute treatment of manic or mixed episodes associated with pediatric bipolar I disorder in patients aged 10-17 years. For 6- to 17-year-old patients, aripiprazole is also indicated for treatment of irritability associated with autistic disorder. ${ }^{36-41}$

Herein, we review and discuss the effectiveness of aripiprazole for bipolar disorder in children and adolescents, with particular focus on the drug's pharmacological profile and various clinical study outcomes.

\section{Literature review}

We performed a literature review utilizing the following PubMed search terms: 'aripiprazole', 'bipolar I disorder', 'bipolar II disorder', 'bipolar disorder', 'bipolar spectrum disorder', 'pediatric bipolar disorder', 'mixed episode', 'mixed state', 'mixed depression', 'bipolar mania', and 'mania'. Additionally, randomized controlled trials (RCTs); 'human trials'; and 'English language' were applied as limits. The references of selected articles were checked for additional articles, including those on non-RCTs. Selected studies were required to include children and adolescents in the study population, and to have standardized assessment of bipolar disorder as a primary outcome measure. We identified three RCTs that met these criteria as well as four non-RCTs.

\section{Aripiprazole pharmacological profile Affinity for dopamine D2 receptors and intrinsic activity}

Aripiprazole employs a mechanism of action that is distinctive from those of other atypical antipsychotics, and thus is classified as a third-generation atypical antipsychotic drug. ${ }^{42}$ As a partial agonist of dopamine D2, aripiprazole appropriates intrinsic activity at this molecule's receptors. Through this mechanism, dopamine D2 receptor-mediated neurotransmission is stabilized but not excessively blocked; thus, aripiprazole is often referred to as a dopamine system stabilizer. ${ }^{43}$ Compared to endogenous dopamine, aripiprazole shows higher affinity to dopamine $\mathrm{D} 2$ receptors, and is 
therefore less likely than other antipsychotics to raise serum prolactin and result in extrapyramidal symptoms (EPS). Several other partial agonists also reduce negative symptoms and lower EPS incidence; however, none has shown non-inferiority to typical antipsychotics with regard to reducing other psychotic symptoms, eg, positive symptoms. ${ }^{44-49}$ Aripiprazole differs from other partial agonists in its higher extent of intrinsic activity at dopamine D2 receptors. It is notable that aripiprazole also has high affinity as a partial agonist of dopamine D3 receptors. ${ }^{44,50}$

\section{Aripiprazole affinity at serotonin $5 \mathrm{HT}$ receptors}

Aripiprazole also demonstrates high affinity at serotonin 5-HT1A and 5-HT2A receptors. Anxiety behavior is observed in 5-HT1A knockout mice, ${ }^{51}$ while treatment with 5-HT1A receptor agonists reportedly improves cognitive function and reduces symptoms of depression and anxiety. ${ }^{52}$ As a high-affinity partial agonist of serotonin 5-HT1A, aripiprazole could reduce depression and anxiety, as well as antipsychotic-derived EPS. ${ }^{53,54}$ Genetic variations in 5-HT2A receptors reportedly influence human episodic memory, suggesting a close relationship between this receptor and cognitive function. ${ }^{55,56}$ Aripiprazole's high-affinity antagonist activity against these receptors likely contributes to its ability to improve negative symptoms while reducing antipsychotic-induced EPS. ${ }^{57}$

Wirshing et $\mathrm{al}^{58}$ reported an association between weight gain and the use of second-generation antipsychotics (eg, olanzapine, risperidone, and clozapine) that block histamine and serotonin $5 \mathrm{HT}$ receptors. It has also been suggested that the $5 \mathrm{HT} 2 \mathrm{C}$ receptor agonist $\mathrm{m}$-chlorophenyl piperazine (m-CPP) continues to activate brain 5-HT2C receptors, thus reducing appetite and body weight. ${ }^{59}$ Furthermore, significant weight increases were reported following olanzapine and risperidone treatment in drug-naïve patients with 5HT2C polymorphisms compared to those with wild-type 5HT2C, indicating that antipsychotic-related weight gain may be influenced by $5 \mathrm{HT} 2 \mathrm{C}$ genetic variations. ${ }^{60}$ Overall, it appears that weight gain is associated with $5 \mathrm{HT} 2 \mathrm{C}$ antagonists, while the partial 5HT2C receptor antagonism of aripiprazole has anti-obesity effects.

\section{Aripiprazole affinities for other receptors}

Aripiprazole is also an antagonist of histamine $\mathrm{H} 1$, adrenaline $\alpha 1,{ }^{61}$ and muscarinic M1 receptors. ${ }^{62}$ High-affinity histamine $\mathrm{H} 1$ receptor antagonists are associated with weight gain and hypersedation, ${ }^{61-63}$ and high-affinity muscarinic
M1 receptor antagonists are linked to anticholinergic side effects, including dry mouth, urinary retention, constipation, blurred vision, or effects on cognitive function. ${ }^{63-66}$ However, aripiprazole has a low affinity for these receptors, and thus carries low rates of these side effects, ${ }^{67}$ as described in the American Psychiatric Association (APA) guidelines. ${ }^{68}$

\section{Aripiprazole metabolism and pharmacokinetic profile}

Aripiprazole is typically administered once per day. In children and adolescents, it takes 2 hours to reach maximum serum concentration $\left(\mathrm{T}_{\max }\right),{ }^{34,69}$ and studies in adults show that it has a 75 -hour serum half-life $\left(\mathrm{T}_{1 / 2}\right) \cdot{ }^{70}$ Within 14 days of aripiprazole dosing, steady-state concentrations are reached, at which point dose-proportional pharmacokinetics are observed. Aripiprazole is eliminated primarily via hepatic metabolism involving CYP3A4, CYP2D6, and two P450 isozymes, and thus may interact with drugs that strongly induce or inhibit these enzymes. However, aripiprazole does not induce or inhibit these or any other cytochrome P450 (CYP) enzymes. ${ }^{34,70}$ Food intake does not influence aripiprazole absorption.

Investigations of aripiprazole pharmacokinetic parameters, with adjustment for body weight, show results that are consistent between children and adolescents with autistic disorders and adults. ${ }^{70-72}$ Children and adolescents given $2-15 \mathrm{mg}$ aripiprazole daily to manage conduct disorder showed a linear pharmacokinetic profile over 14 days of treatment, with a mean maximum plasma concentration $\left(\mathrm{C}_{\max }\right)$ of 21.8-194.2 ng/mL, a median time to $\mathrm{C}_{\max }\left(\mathrm{T}_{\max }\right)$ of 2-4 hours, a mean area under the plasma concentration time curve (AUC) of 800-3,879 ng · hour/mL, and a mean weightnormalized apparent oral total body clearance (CLT/F) of $0.03-0.07 \mathrm{~L} /$ hour $/ \mathrm{kg}^{73}$

\section{Efficacy of aripiprazole in bipolar disorder in children and adolescents RCTs}

Findling et $\mathrm{al}^{40}$ performed a double-blind, randomized, placebo-controlled trial in patients with bipolar I disorder with current manic or mixed episodes ( $n=296$; age range: 10-17 years). Within 1 week, they reported that a daily dosage of $10 \mathrm{mg}$ or $30 \mathrm{mg}$ aripiprazole led to significant improvement in the total Young Mania Rating Scale (YMRS) score. After the 4-week follow-up period, significantly more aripiprazole-treated patients showed a $\geq 50 \%$ reduction in total YMRS score compared to patients in the placebo group. These results suggested strong efficacy of aripiprazole 


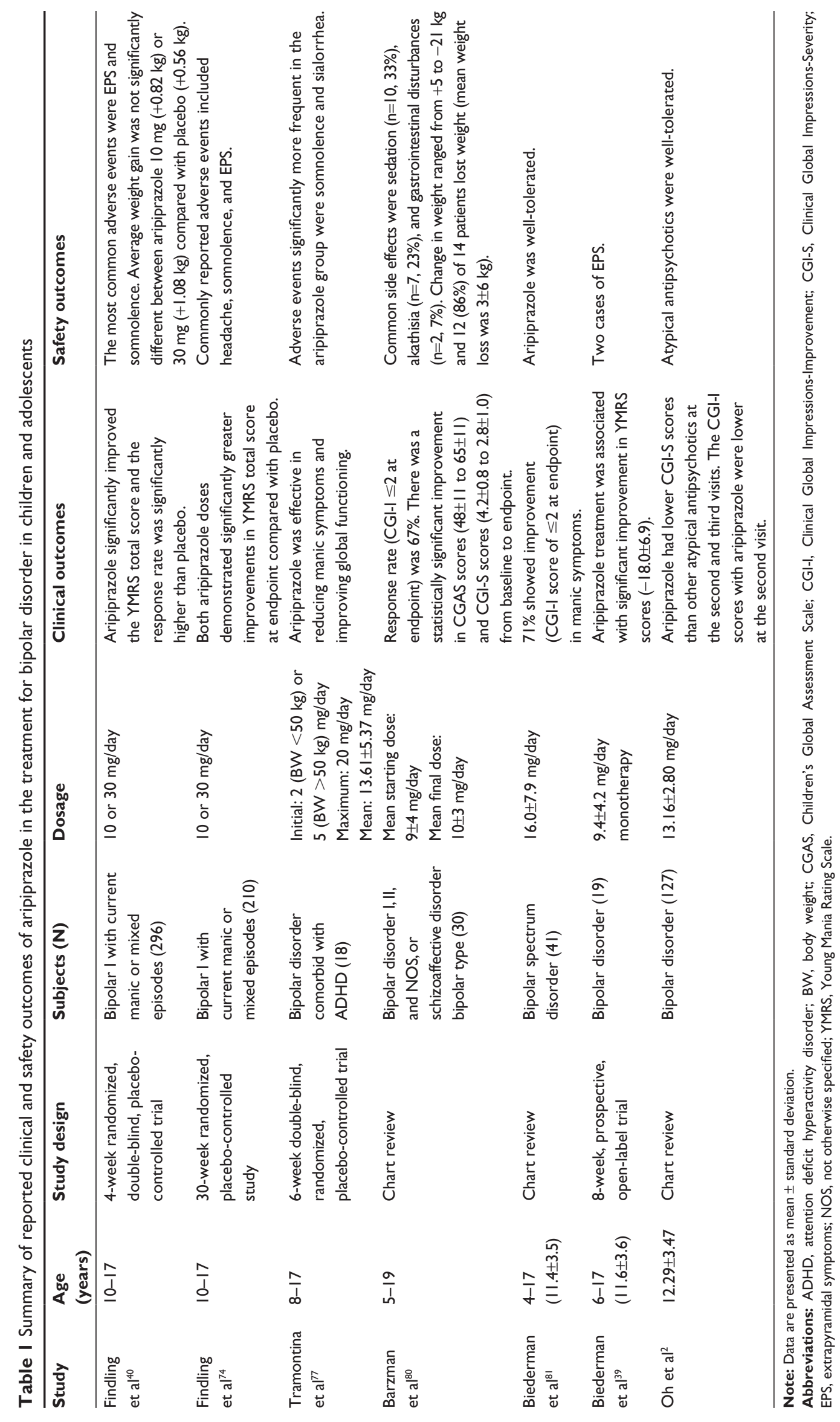


administered for acute-stage bipolar disorder in children and adolescents. Somnolence and EPS were the most commonly reported adverse events, with higher rates among the patients who received aripiprazole $30 \mathrm{mg}$ than aripiprazole $10 \mathrm{mg}$. No significant difference in average weight gain was observed among the two different dosage groups and the placebo group: aripiprazole $10 \mathrm{mg},+0.82 \mathrm{~kg}$; aripiprazole $30 \mathrm{mg},+1.08 \mathrm{~kg}$; placebo group $+0.56 \mathrm{~kg}$.

In the follow-up report of the same study, ${ }^{74}$ the acute double-blind treatment was extended for up to 26 weeks $(\mathrm{n}=210$; age range: $10-17$ years). This extended study was completed by $32.4 \%$ of the patients: $45.3 \%$ receiving aripiprazole $10 \mathrm{mg} /$ day, $31.0 \%$ aripiprazole $30 \mathrm{mg} /$ day, and $18.8 \%$ placebo. Total YMRS score improvements were significantly greater $(P<0.001)$ with both aripiprazole doses compared with placebo at the endpoint in the protocol-specified last observation carried forward analyses. However, this difference was not found in the observed case or mixed-model repeated measures at week 30 . All analyses showed that, compared to placebo, both aripiprazole doses produced better results regarding response rates, and the Children's Global Assessment Scale (CGAS) of Functioning and Clinical Global Impressions (CGI): Bipolar severity of overall and mania scores at endpoint. Headache, somnolence, and EPS were the most frequently reported side effects. Compared to placebo, both doses of aripiprazole showed longer overall time to all-cause discontinuation - aripiprazole $10 \mathrm{mg} /$ day, 15.6 weeks; aripiprazole $30 \mathrm{mg} /$ day, 9.5 weeks; placebo, 5.3 weeks; $P<0.05$ for both dose groups versus placebo - thus, both aripiprazole dosages were generally well-tolerated and superior to placebo. However, low completion rates were observed in each group, despite the treatment benefits. ${ }^{74}$

In a post-hoc analysis ${ }^{75}$ of the results of the 4 -week, multicenter, double-blind, randomized placebo-controlled study of Findling et al, ${ }^{40} 296$ eligible subjects were randomized to three groups: 98 patients received aripiprazole $10 \mathrm{mg} /$ day, 99 patients (of 10-17 years of age) received aripiprazole $30 \mathrm{mg} /$ day, and 99 patients received placebo. The 4-week study was completed by 237 patients (80.1\%). Eleven YMRS line items were evaluated, of which seven were significantly improved in both aripiprazole treatment groups compared to in the placebo group. The greatest effect sizes were observed in the following YMRS line items: irritability (effect size of 0.7 ; treatment effect of $1.43 ; P<0.001$ ), aggressive behavior (effect size of 0.7 ; treatment effect of $1.38 ; P<0.001$ ), and increased motor activity/energy (effect size of 0.6; treatment effect of $0.86 ; P<0.001$ ). These findings indicated that treatment with aripiprazole led to improvements in a broad range of symptoms included in the YMRS scale. ${ }^{17}$ A secondary analysis ${ }^{76}$ of the results from the same study ${ }^{40}$ reviewed the data from patients $(n=296$; age range: $10-17$ years) who had a bipolar I disorder-associated acute manic/mixed episode and who were randomized to receive $10 \mathrm{mg}$ or $30 \mathrm{mg}$ aripiprazole per day or placebo. Defining a response as a $\geq 33 \%$ reduction in total YMRS score, the response rates were $73 \%$ for aripiprazole $10 \mathrm{mg}$ / day (number needed to treat $[\mathrm{NNT}]=3$ ), $77 \%$ for aripiprazole $30 \mathrm{mg} /$ day $(\mathrm{NNT}=3$ ), and 38\% for placebo. Application of the more stringent response definition of a $\geq 50 \%$ reduction in total YMRS score resulted in a generally lower magnitude of the response to treatment with aripiprazole or placebo: aripiprazole $10 \mathrm{mg} /$ day, $45 \%, \mathrm{NNT}=5$; aripiprazole $30 \mathrm{mg} /$ day, $64 \%$, NNT =3; placebo, $25.5 \% .^{76}$

Tramontina et al ${ }^{77}$ performed a placebo-controlled double-blind trial to assess the response to aripiprazole treatment for bipolar disorder with comorbid attentiondeficit/hyperactivity disorder (ADHD) among children and adolescents. Over 6 weeks from baseline to endpoint, scores of CGI-Severity (CGI-S), YMRS, and the Child Mania Rating Scale: Parental Version were reduced to a significantly greater degree in the aripiprazole-treated group ( $\mathrm{n}=18$; age range: $8-17$ years) compared to the placebo group $(n=25)$. The aripiprazole group also showed higher remission and response rates compared to placebo. Weight and ADHD and depressive symptoms did not significantly differ between groups. Sialorrhea and somnolence were reported significantly more frequently in the aripiprazole group. Overall, aripiprazole appeared to effectively improve global functioning and reduce symptoms of mania without associated weight gain or severe adverse events. However, as the study population presented comorbid conditions, the conclusions must be cautiously evaluated. ${ }^{77}$

A network meta-analysis ${ }^{78}$ included studies that compared antipsychotic treatment with aripiprazole, ${ }^{40,77}$ olanzapine, ${ }^{28}$ quetiapine, ${ }^{79}$ and risperidone ${ }^{26}$ to administration of placebo at week 3 . The results showed significantly better YMRS responses with aripiprazole compared with placebo. However, no significant differences were observed between aripiprazole and the other three second-generation antipsychotics.

\section{Non-RCTs}

Barzman et ${ }^{80}$ reviewed the medical charts for 30 aripiprazole-treated cases of schizoaffective disorder bipolar type, or bipolar disorder I, II, or not otherwise 
specified among children and adolescents (age range: 5-19 years; mean starting dose of aripiprazole: $9 \pm 4 \mathrm{mg} /$ day; mean final dose of aripiprazole: $10 \pm 3 \mathrm{mg} /$ day). With response defined as a final CGI-Improvement (CGI-I) score of $\leq 2$, the overall response rate was $67 \%$. From baseline to the study endpoint, the patients showed significantly improved CGI-S scores ( $4.2 \pm 0.8$ to $2.8 \pm 1.0$; signed rank of $-172 ; P<0.0001$; effect size of 1.90) and CGAS scores ( $48 \pm 11$ to $65 \pm 11$; signed rank of $191 ; P<0.0001$ ). The patients commonly reported several side effects - including sedation $(n=10,33 \%)$, akathisia $(n=7,23 \%)$, and gastrointestinal disturbances $(\mathrm{n}=2,7 \%)$ - but no serious adverse events were reported. Body weight measurements were available for 14 patients (47\%) with 12 of the 14 patients (86\%) showing weight loss (mean weight loss: $3 \pm 6 \mathrm{~kg}$ ), and the weight changes from baseline to endpoint ranging from +5 to $-21 \mathrm{~kg} .{ }^{80}$

In another chart review, Biederman et $\mathrm{al}^{81}$ identified 41 pediatric patients with bipolar spectrum disorder who were treated with aripiprazole (age range: 4-17 years; average dose: $16.0 \pm 7.9 \mathrm{mg}$ /day; average treatment duration: 4.6 months). Of these patients, $71 \%$ showed improvement in manic symptoms based on a CGI-I score of $\leq 2$ at endpoint. The aripiprazole treatment was well-tolerated. ${ }^{81}$ Biederman's group later conducted a prospective open-label trial $(n=19$; age range: $6-17$ years). ${ }^{39}$ The 8 -week study was completed by $15(79 \%)$ of the included 19 bipolar pediatric patients (age range: 6-17 years). Aripiprazole monotherapy with a daily dose of $9.4 \pm 4.2 \mathrm{mg}$ was associated with significant and clinically important improvements in mean YMRS scores $(-18.0 \pm 6.9 ; P<0.0001)$. Two patients dropped out due to EPS; however, aripiprazole was well-tolerated in all other cases and did not lead to significantly increased body weight $(1.8 \pm 1.7 \mathrm{~kg} ; P=0.2) .{ }^{39}$

Oh et $\mathrm{al}^{2}$ reviewed medical records from 127 cases of pediatric bipolar disorder (age range: 4-18 years; mean age: $12.29 \pm 3.47$ years) including $91(71.7 \%)$ male and $36(28.3 \%)$ female patients. Among this patient population, 62 patients $(48.8 \%)$ received aripiprazole (average dose: $13.16 \pm 2.80 \mathrm{mg} /$ day), 52 (40.9\%) risperidone, eleven (8.7\%) quetiapine, and two (1.6\%) paliperidone. CGI-S scores at patient visits two and three were lower in the aripiprazole treatment group compared to in the other treatment groups. CGI-I scores at visit two were also lower within the aripiprazole treatment group. All administered atypical antipsychotic treatments were well-tolerated, leading to no serious side effects. The authors concluded that, in the early phase of treatment, aripiprazole may be more effective than other atypical antipsychotics (Table 1). ${ }^{2}$

\section{Aripiprazole safety data in children and adolescents Body weight and metabolic parameters}

As mentioned in the section "Aripiprazole metabolism and pharmacokinetic profile", aripiprazole is less associated with weight gain compared to other antipsychotics due to its low affinity for histamine $\mathrm{H} 1$ receptors, and its partial antagonism of the weight gain- and obesity-associated serotonin 5-HT2C receptors. ${ }^{53,54,67}$ In the nonrandomized Second-Generation Antipsychotic Treatment Indications, Effectiveness and Tolerability in Youth (SATIETY) cohort study, Correll et al ${ }^{66}$ evaluated cardiometabolic effects following a median of 10.8 weeks of treatment with second-generation antipsychotics among 338 patients of 4-19 years of age who were naïve to antipsychotic medication. Over the course of treatment, mean body weight increased by $8.5 \mathrm{~kg}$ among patients treated with olanzapine ( $\mathrm{n}=45), 6.1 \mathrm{~kg}$ in the quetiapine treatment group $(\mathrm{n}=36), 5.3 \mathrm{~kg}$ with risperidone treatment $(\mathrm{n}=135), 4.4 \mathrm{~kg}$ with aripiprazole ( $\mathrm{n}=41)$, and only $0.2 \mathrm{~kg}$ among untreated patients $(n=15)$. The groups treated with olanzapine and quetiapine, respectively, showed significant increases in the mean levels of total cholesterol (15.6-24.3 mg/dL and 9.1-17.7 mg/dL), triglycerides (24.3-38.9 mg/dL and 37.0-63.8 mg/dL), non-high density lipoprotein (HDL) cholesterol (16.8-24.3 mg/dL and 9.9-18.4 mg/dL), and the ratio of triglycerides to HDL cholesterol (0.6-0.9 and 1.2-2.0). The risperidone treatment group showed significantly increased triglycerides $(9.7-19.0 \mathrm{mg} / \mathrm{dL})$. No significant metabolic changes were detected between baseline and endpoint in the aripiprazole or untreated groups.

Fraguas et al ${ }^{82}$ reviewed studies of second- and third-generation antipsychotic use in children and adolescents with psychotic and bipolar spectrum disorders, analyzing the mean weight gains across the studies. In placebo groups, mean weight changes ranged from $-0.8 \mathrm{~kg}$ to $+2.5 \mathrm{~kg}$. The mean weight gain ranges among treated patients were as follows: olanzapine: $+3.8 \mathrm{~kg}$ to $+16.2 \mathrm{~kg}(\mathrm{n}=353)$; clozapine: $+0.9 \mathrm{~kg}$ to $9.5 \mathrm{~kg}(\mathrm{n}=97)$; risperidone: $+1.9 \mathrm{~kg}$ to $+7.2 \mathrm{~kg}(\mathrm{n}=571)$; quetiapine: $+2.3 \mathrm{~kg}$ to $+6.1 \mathrm{~kg}(\mathrm{n}=133)$; and aripiprazole: $0 \mathrm{~kg}$ to $+4.4 \mathrm{~kg}(\mathrm{n}=451){ }^{82}$

Of the studies that have evaluated weight gain among atypical antipsychotic-treated children and adolescents, most are observational and involve only a short treatment period. ${ }^{83,84}$ Findling et al ${ }^{85}$ performed a long-term placebocontrolled trial in autistic children, and reported that, 
compared to placebo recipients, aripiprazole-treated patients exhibited a higher average weight gain $(+1.6 \mathrm{~kg})$. The results of a network meta-analysis ${ }^{78}$ indicate that aripiprazole use leads to less weight gain than the use of olanzapine or quetiapine. Although the available data suggest that aripiprazole causes less weight gain than other atypical antipsychotics, weight should still be carefully monitored throughout aripiprazole treatment.

\section{EPS and akathisia}

To our knowledge, there is not yet a conclusive report of the akathisia prevalence among children and adolescents treated with aripiprazole for bipolar disorder. Multiple randomized, double-blinded, placebo-controlled trials in aripiprazole-treated children and adolescents with schizophrenia, ${ }^{86}$ bipolar type I disorder, ${ }^{40}$ and autism ${ }^{36,37}$ have reported more frequent EPS occurrence following administration of aripiprazole than placebo. Such instances of EPS have included tremor, salivation, and dystonia, but of a mild-to-moderate degree. Patients treated with a high dose of aripiprazole (30 mg/day) were reported to more commonly display akathisia, but this prevalence was comparable to those observed in groups receiving aripiprazole $10 \mathrm{mg} /$ day or placebo. ${ }^{86}$

Among patients with bipolar I disorder, Findling et $\mathrm{al}^{40}$ reported a higher akathisia rate in those given aripiprazole $10 \mathrm{mg} /$ day or greater compared with the control group. However, other publications have reported comparable rates of akathisia occurrence between aripiprazole-treated and placebo groups. ${ }^{36,37}$ Overall, there is not yet any consensus regarding rate of akathisia among aripiprazole-treated patients. However, it seems likely that akathisia may occur more frequently in aripiprazole-treated children and adolescent patients who receive higher doses. ${ }^{40,86}$

\section{Sedation}

Since aripiprazole has only a low affinity for histamine $\mathrm{H} 1$ receptors, ${ }^{67}$ it is associated with a low incidence of oversedation among pediatric patients with schizophrenia ${ }^{86}$ or autism. ${ }^{36,37}$ As is the case with other childhood psychiatric disorders, aripiprazole treatment for bipolar disorder was not associated with any reported adverse events of sedation; however, sleepiness has been more commonly observed following aripiprazole treatment compared to placebo. ${ }^{40}$ Higher aripiprazole dosage is considered to more frequently induce sleepiness and sedation in children and adolescents. ${ }^{40,86}$

\section{Serum prolactin}

Randomized, double-blinded, placebo-controlled trials in patients with schizophrenia, ${ }^{86}$ bipolar type I disorder, ${ }^{40}$ or autism ${ }^{36,37}$ have reported significantly lower serum prolactin levels following aripiprazole administration compared to at baseline, as well as in aripiprazole treatment groups compared to placebo groups. In their review, Fraguas et $\mathrm{al}^{82}$ found that prolactin levels were most increased among risperidone-treated patients (range of mean change: $8.3 \mathrm{ng} / \mathrm{mL}$ to $49.6 \mathrm{ng} / \mathrm{mL}$ ), followed by olanzapine-treated patients (range of mean change: $-1.5 \mathrm{ng} / \mathrm{mL}$ to $+13.7 \mathrm{ng} / \mathrm{mL}$ ), while aripiprazole treatment was associated with lower prolactin levels, and clozapine treatment and quetiapine treatment had no impact on prolactin. ${ }^{82}$ A Cochrane review meta-analysis ${ }^{35}$ states that aripiprazole treatment in children and adolescents often reduced prolactin levels to below the normal range. Similarly, the systemic review by Safer et $\mathrm{al}^{87}$ revealed that $60 \%$ of pediatric and adult aripiprazoletreated patients exhibited subnormal prolactin serum levels compared to only $8 \%$ of unmedicated control subjects. The frequency of prolactin subnormality following aripiprazole treatment was twice as frequent in children as in adolescents and was minimal in adults. Serum prolactin level reduction is reportedly more prominent with higher aripiprazole dosage and with increased duration of treatment. ${ }^{87}$ The network meta-analysis ${ }^{78}$ revealed a lower prolactin increase following treatment with aripiprazole compared to with risperidone, olanzapine, or quetiapine.

\section{Cardiac effects}

No published double-blinded, placebo-controlled trial of aripiprazole in children and adolescents has demonstrated evidence of changes in heart rate, blood pressure, electrocardiogram, or QTc interval. ${ }^{36,37,86}$ One prospective, open-label study ( $n=25$; age range: $5-17$ years) investigated aripiprazole use for treating irritability in cases of Asperger's disorder and pervasive developmental disorder not otherwise specified, and found no significant changes in the PR, QRS, RR, and QTc intervals after 14 weeks of aripiprazole therapy. ${ }^{88}$ The posttreatment QTc values were all below $440 \mathrm{~ms}$, and the administered dosage was not significantly correlated with the percent change in QTc. ${ }^{88}$ These results suggest that aripiprazole does not significantly impact cardiac health and carries a low risk of causing sudden death.

Another prospective open-label study ${ }^{89}$ investigated children and adolescents with psychiatric disorders $(n=60$; age range: 4-15 years) who received new prescriptions for mono- 
therapy with aripiprazole ( $\mathrm{n}=29$; mean dosage: $7.4+3.1 \mathrm{mg} /$ day $)$ or risperidone $(\mathrm{n}=31$; mean dosage: $1.5+1 \mathrm{mg} /$ day $)$. The patients each underwent electrocardiography before starting the new prescription as well as 2 months after administration. The results showed no pathological values of QT (QTc) or QT dispersion (QTd) in any patients, before or after treatment with either agent. However, the use of risperidone was associated with slight increases over time in both mean QTc (407.4+11.9 ms before administration vs $411.2+13.0 \mathrm{~ms}$ after 2 months; $P<0.05)$ and QTd $(40.0+4.4 \mathrm{~ms}$ before administration vs $44.7+5.5 \mathrm{~ms}$ after 2 months; $P<0.001$ ). On the other hand, the use of aripiprazole did not lead to any change of mean QTc, and resulted in only a slight increase of QTd (40.6+6.5 ms before administration vs $46.3+7.2 \mathrm{~ms}$ after 2 months; $P<0.01)$. The authors concluded that both drugs can be used in children without leading to clinically relevant modifications of QT interval. ${ }^{89}$

\section{Gastrointestinal disturbances}

A Cochrane review meta-analysis based on ten studies $(n=3,340)$ including both adults and children/adolescents reported that aripiprazole treatment carried a risk of gastrointestinal disturbances. ${ }^{35}$

\section{Place in therapy}

Aripiprazole is used to improve emotional stability and also has antianxiety, sedative, and antidepressive effects. The high tolerability of this drug enables its safe administration to children and adolescents. Aripiprazole carries a low risk of condition deterioration - for example, acting out, manic switch, or disinhibition - and it can easily achieve rapid stabilization when administered to children and adolescents with bipolar disorders. As antidepressants are not established to be safe for use in children and adolescents, the antidepressant effect of aripiprazole is highly valuable, especially in the treatment of bipolar depression.

Compared to typical antipsychotic drugs, aripiprazole is associated with lower rates of side effects, including sedation, weight gain, metabolic disorders, hyperprolactinemia, and EPS. To permit continuous treatment, a lower rate of side effects could be considered to be more critical in children and adolescents than in adults. In their review, Greenaway and Elbe stated that aripiprazole use seems to minimally influence the metabolic profile in children and adolescents compared with most other atypical antipsychotics. ${ }^{34}$ Overall, aripiprazole appears to represent an important treatment option for some pediatric patients who experience poor efficacy or substantial adverse metabolic effects with other antipsychotic medications. ${ }^{34}$
It must also be noted that there is not yet evidence showing that aripiprazole has superior efficacy compared to other second-generation antipsychotics. ${ }^{78}$ Aripiprazole has been recommended by the National Institute for Health and Care Excellence (NICE) in the UK. However, the Evidence Review Group (ERG) - an external academic organization independent of NICE - has critiqued the available clinical evidence regarding aripiprazole and its interpretation. ${ }^{78}$ There currently exists only limited evidence recommending any specific role for aripiprazole in clinical treatment. Moreover, the licensed authorization may not represent an accurate reflection of real-world prescribing practices, for example, regarding the restriction to 12 weeks of treatment. Aripiprazole is presently the only atypical antipsychotic that is licensed in the UK for administration to adolescents over 13 years of age with bipolar I disorder. However, there is not currently sufficient evidence to allow NICE to recommend that aripiprazole hold a specific position in the treatment pathway as compared with other second-generation antipsychotics commonly used in this patient population. ${ }^{78}$

\section{Limitations}

This study has several limitations. First, only a limited number of RCTs have investigated the tolerability and efficacy of aripiprazole for treatment of bipolar disorder in children and adolescents. Therefore, conclusions drawn from the available studies must be cautiously evaluated, and there remains a need for additional data from controlled studies and head-to-head comparison studies. Second, there are also few studies that have evaluated the consequences of long-term aripiprazole treatment. Third, in light of the diversity or heterogeneity and the various phases of bipolar disorder, few studies have investigated optimal treatment for each subtype (such as bipolar I, bipolar II, bipolar spectrum disorder, or temper dysregulation disorder with dysthymia) or phase (such as bipolar depression, bipolar mania, acute mania, hypomania, mixed episode, or maintenance treatment phase) in children and adolescents. Fourth, aripiprazole's specific mechanism of action that results in its efficacy against bipolar disorder remains to be elucidated. Further investigations are needed to shed additional light on these issues.

\section{Conclusion}

The presently reviewed RCTs and non-RCTs have generally concluded that aripiprazole appears to be an effective and well-tolerated treatment for bipolar disorder among children and adolescents, although the number of RCTs remains 
limited. Compared to other antipsychotic medications, aripiprazole leads to lower rates of adverse events that often lead to drug discontinuation. However, there is not yet sufficient evidence to suggest that aripiprazole is more effective compared to other second-generation antipsychotics. Hence, it is impossible to recommend aripiprazole more highly than other second-generation antipsychotics for the treatment of bipolar disorder in children and adolescents. Future headto-head comparison studies are needed to produce the data required to make such recommendations.

\section{Disclosure}

The author reports no conflicts of interest in this work.

\section{References}

1. Freeman AJ, Youngstrom EA, Michalak E, Siegel R, Meyers OI, Findling RL. Quality of life in pediatric bipolar disorder. Pediatrics. 2009;123(3):e446-e452.

2. Oh J, Chang JG, Lee SB, Song DH, Cheon KA. Comparison of aripiprazole and other atypical antipsychotics for pediatric bipolar disorder: a retrospective chart review of efficacy and tolerability. Clin Psychopharmacol Neurosci. 2013;11(2):72-79.

3. Soutullo CA, Chang KD, Díez-Suárez A, et al. Bipolar disorder in children and adolescents: international perspective on epidemiology and phenomenology. Bipolar Disord. 2005;7(6):497-506.

4. Stringaris A, Santosh P, Leibenluft E, Goodman R. Youth meeting symptom and impairment criteria for mania-like episodes lasting less than four days: an epidemiological enquiry. J Child Psychol Psychiatry. 2010;51(1):31-38.

5. Brunelle J, Consoli A, Tanguy ML, et al. Phenomenology, sociodemographic factors and outcome upon discharge of manic and mixed episodes in hospitalized adolescents: a chart review. Eur Child Adolesc Psychiatry. 2009;18(3):185-193.

6. Zuddas A, Zanni R, Usala T. Second generation antipsychotics (SGAs) for non-psychotic disorders in children and adolescents: a review of the randomized controlled studies. Eur Neuropsychopharmacol. 2011;21(8):600-620.

7. Youngstrom E, Van Meter A, Algorta GP. The bipolar spectrum: myth or reality? Curr Psychiatry Rep. 2010;12(6):479-489.

8. Van Meter AR, Moreira AL, Youngstrom EA. Meta-analysis of epidemiologic studies of pediatric bipolar disorder. J Clin Psychiatry. 2011;72(9):1250-1256.

9. Chang KD. The use of atypical antipsychotics in pediatric bipolar disorder. J Clin Psychiatry. 2008;69 Suppl 4:4-8.

10. Moreno C, Laje G, Blanco C, Jiang H, Schmidt AB, Olfson M. National trends in the outpatient diagnosis and treatment of bipolar disorder in youth. Arch Gen Psychiatry. 2007;64(9):1032-1039.

11. Goodwin GM, Martinez-Aran A, Glahn DC, Vieta E. Cognitive impairment in bipolar disorder: neurodevelopment or neurodegeneration? An ECNP expert meeting report. Eur Neuropsychopharmacol. 2008;18(11):787-793.

12. Perlis RH, Miyahara S, Marangell LB, et al. Long-term implications of early onset in bipolar disorder: data from the first 1000 participants in the systematic treatment enhancement program for bipolar disorder (STEP-BD). Biol Psychiatry. 2004;55(9):875-881.

13. Carter TD, Mundo E, Parikh SV, Kennedy JL. Early age at onset as a risk factor for poor outcome of bipolar disorder. $J$ Psychiatr Res. 2003;37(4):297-303.

14. Lin PI, McInnis MG, Potash JB, et al. Clinical correlates and familial aggregation of age at onset in bipolar disorder. Am J Psychiatry. 2006;163(2):240-246.
15. Leverich GS, Post RM, Keck PE Jr, et al. The poor prognosis of childhood-onset bipolar disorder. J Pediatr. 2007;150(5):485-490.

16. Post RM, Kowatch RA. The health care crisis of childhood-onset bipolar illness: some recommendations for its amelioration. J Clin Psychiatry. 2006;67(1):115-125.

17. Mankoski R, Zhao J, Carson WH, Mathew SJ, Forbes RA. Young mania rating scale line item analysis in pediatric subjects with bipolar I disorder treated with aripiprazole in a short-term, double-blind, randomized study. J Child Adolesc Psychopharmacol. 2011;21(4):359-364.

18. Doey T. Aripiprazole in pediatric psychosis and bipolar disorder: a clinical review. J Affect Disord. 2012;138 Suppl:S15-S21.

19. Vieta E. Atypical antipsychotics in the treatment of mood disorders. Curr Opin Psychiatry. 2003;16(1):23-27.

20. Vieta E, Bourin M, Sanchez R, et al; Aripoprazole Study Group. Effectiveness of aripiprazole $\mathrm{v}$. haloperidol in acute bipolar mania: double-blind, randomised, comparative 12-week trial. Br J Psychiatry. 2005; 187:235-242.

21. Tohen M, Goldberg JF, Gonzalez-Pinto Arrillaga AM, et al. A 12-week, double-blind comparison of olanzapine vs haloperidol in the treatment of acute mania. Arch Gen Psychiatry. 2003;60(12):1218-1226.

22. Brecher M, Huizar K. Quetiapine monotherapy for acute mania associated with bipolar disorder. International Conference on Bipolar Disorder (abstract); June 12-14, 2003; Pittsburgh, PA.

23. McClellan J, Kowatch R, Findling RL; Work Group on Quality Issues. Practice parameter for the assessment and treatment of children and adolescents with bipolar disorder. JAm Acad Child Adolesc Psychiatry. 2007;46(1):107-125.

24. Kowatch RA, Fristad M, Birmaher B, et al. Treatment guidelines for children and adolescents with bipolar disorder. JAm Acad Child Adolesc Psychiatry. 2005;44(3):213-235.

25. Correll CU. Assessing and maximizing the safety and tolerability of antipsychotics used in the treatment of children and adolescents. J Clin Psychiatry. 2008;69 Suppl 4:26-36.

26. Haas M, Delbello MP, Pandina G, et al. Risperidone for the treatment of acute mania in children and adolescents with bipolar disorder: a randomized, double-blind, placebo-controlled study. Bipolar Disord. 2009;11(7):687-700.

27. Delbello MP, Schwiers ML, Rosenberg HL, Strakowski SM. A double-blind, randomized, placebo-controlled study of quetiapine as adjunctive treatment for adolescent mania. J Am Acad Child Adolesc Psychiatry. 2002;41(10):1216-1223.

28. Tohen M, Kryzhanovskaya L, Carlson G, et al. Olanzapine versus placebo in the treatment of adolescents with bipolar mania. Am J Psychiatry. 2007;164(10):1547-1556.

29. Keck PE Jr, Marcus R, Tourkodimitris S, et al. A placebo-controlled, double-blind study of the efficacy and safety of aripiprazole in patients with acute bipolar mania. Am J Psychiatry. 2003;160(9): $1651-1658$

30. Kikuchi T. The research and development of aripiprazole and its mechanism of action. Jpn J Clin Psychopharmacol. 2007;10(3): 464-468.

31. Kirino E. Efficacy and safety of aripiprazole in child and adolescent patients. Eur Child Adolesc Psychiatry. 2012;21(7):361-368.

32. Kirino E. Aripiprazole in patients with autistic spectrum disorders: a review and case reports. Autism Open Access. 2012;S1:004.

33. Kirino E. Efficacy and tolerability of pharmacotherapy options for the treatment of irritability in autistic children. Clin Med Insights Pediatr. 2014;8:17-30

34. Greenaway M, Elbe D. Focus on aripiprazole: a review of its use in child and adolescent psychiatry. $J$ Can Acad Child Adolesc Psychiatry. 2009;18(3):250-260.

35. Brown R, Taylor MJ, Geddes J. Aripiprazole alone or in combination for acute mania. Cochrane Database Syst Rev. 2013;12:CD005000.

36. Marcus RN, Owen R, Kamen L, et al. A placebo-controlled, fixeddose study of aripiprazole in children and adolescents with irritability associated with autistic disorder. JAm Acad Child Adolesc Psychiatry. 2009;48(11):1110-1119. 
37. Owen R, Sikich L, Marcus RN, et al. Aripiprazole in the treatment of irritability in children and adolescents with autistic disorder. Pediatrics. 2009;124(6):1533-1540.

38. Sanford M, Keating GM. Aripiprazole: in adolescents with schizophrenia. Paediatr Drugs. 2007;9(6):419-423.

39. Biederman J, Mick E, Spencer T, et al. An open-label trial of aripiprazole monotherapy in children and adolescents with bipolar disorder. CNS Spectr. 2007;12(9):683-689.

40. Findling RL, Nyilas M, Forbes RA, et al. Acute treatment of pediatric bipolar I disorder, manic or mixed episode, with aripiprazole: a randomized, double-blind, placebo-controlled study. J Clin Psychiatry. 2009;70(10):1441-1451.

41. Robb AS, Carson WH, Nyilas M, et al. Changes in positive and negative syndrome scale-derived hostility factor in adolescents with schizophrenia treated with aripiprazole: post hoc analysis of randomized clinical trial data. J Child Adolesc Psychopharmacol. 2010;20(1):33-38.

42. Stahl SM. Dopamine system stabilizers, aripiprazole, and the next generation of antipsychotics, part 2: illustrating their mechanism of action. J Clin Psychiatry. 2001;62(12):923-924.

43. Tadori Y, Miwa T, Tottori K, et al. Aripiprazole's low intrinsic activities at human dopamine D2L and D2S receptors render it a unique antipsychotic. Eur J Pharmacol. 2005;515(1-3):10-19.

44. Potkin SG, Saha AR, Kujawa MJ, et al. Aripiprazole, an antipsychotic with a novel mechanism of action, and risperidone vs placebo in patients with schizophrenia and schizoaffective disorder. Arch Gen Psychiatry. 2003;60(7):681-690.

45. Lahti AC, Weiler MA, Corey PK, Lahti RA, Carlsson A, Tamminga CA. Antipsychotic properties of the partial dopamine agonist (-)-3-(3-hy droxyphenyl)-N-n-propylpiperidine(preclamol) in schizophrenia. Biol Psychiatry. 1998;43(1):2-11.

46. Tamminga CA, Carlsson A. Partial dopamine agonists and dopaminergic stabilizers, in the treatment of psychosis. Curr Drug Targets CNS Neurol Disord. 2002;1(2):141-147.

47. Tamminga CA. Partial dopamine agonists in the treatment of psychosis. J Neural Transm. 2002;109(3):411-420.

48. Olbrich R, Schanz H. An evaluation of the partial dopamine agonist terguride regarding positive symptoms reduction in schizophrenics. J Neural Transm Gen Sect. 1991;84(3):233-236.

49. Olbrich R, Schanz H. The effect of the partial dopamine agonist terguride on negative symptoms in schizophrenics. Pharmacopsychiatry. 1988;21(6):389-390.

50. Shapiro DA, Renock S, Arrington E, et al. Aripiprazole, a novel atypical antipsychotic drug with a unique and robust pharmacology. Neuropsychopharmacology. 2003;28(8):1400-1411.

51. Heisler LK, Chu HM, Brennan TJ, et al. Elevated anxiety and antidepressant-like responses in serotonin 5-HT1A receptor mutant mice. Proc Natl Acad Sci U S A. 1998;95(25):15049-15054.

52. Meltzer HY, Li Z, Kaneda Y, Ichikawa J. Serotonin receptors: their key role in drugs to treat schizophrenia. Prog Neuropsychopharmacol Biol Psychiatry. 2003;27(7):1159-1172.

53. DeBattista C, Hawkins J. Utility of atypical antipsychotics in the treatment of resistant unipolar depression. CNS Drugs. 2009;23(5):369-377.

54. Fernandez HH, Trieschmann ME, Friedman JH. Aripiprazole for druginduced psychosis in Parkinson disease: preliminary experience. Clin Neuropharmacol. 2004;27(1):4-5.

55. de Quervain DJ, Henke K, Aerni A, et al. A functional genetic variation of the 5-HT2a receptor affects human memory. Nat Neurosci. 2003;6(11):1141-1142.

56. Grunder G, Kungel M, Ebrecht M, Göröcs T, Modell S. Aripiprazole: pharmacodynamics of a dopamine partial agonist for the treatment of schizophrenia. Pharmacopsychiatry. 2006;39 Suppl 1:S21-S25.

57. Hirose T, Uwahodo Y, Yamada S, et al. Mechanism of action of aripiprazole predicts clinical efficacy and a favourable side-effect profile. $J$ Psychopharmacol. 2004;18(3):375-383.

58. Wirshing DA, Boyd JA, Meng LR, Ballon JS, Marder SR, Wirshing WC. The effects of novel antipsychotics on glucose and lipid levels. J Clin Psychiatry. 2002;63(10):856-865.
59. Sargent PA, Sharpley AL, Williams C, Goodall EM, Cowen PJ. 5-HT2C receptor activation decreases appetite and body weight in obese subjects. Psychopharmacology (Berl). 1997;133(3):309-312.

60. Nasrallah HA. Atypical antipsychotic-induced metabolic side effects: insights from receptor-binding profiles. Mol Psychiatry. 2008;13(1):27-35.

61. Kroeze WK, Hufeisen SJ, Popadak BA, et al. H1-histamine receptor affinity predicts short-term weight gain for typical and atypical antipsychotic drugs. Neuropsychopharmacology. 2003;28(3):519-526.

62. Goodnick PJ, Jerry JM. Aripiprazole: profile on efficacy and safety. Expert Opin Pharmacother. 2002;3(12):1773-1781.

63. Stahl SM, Shayegan DK. The psychopharmacology of ziprasidone: receptor-binding properties and real-world psychiatric practice. J Clin Psychiatry. 2003;64 Suppl 19:6-12.

64. Bolden C, Cusack B, Richelson E. Antagonism by antimuscarinic and neuroleptic compounds at the five cloned human muscarinic cholinergic receptors expressed in Chinese hamster ovary cells. J Pharmacol Exp Ther. 1992;260(2):576-580.

65. Shayegan DK, Stahl SM. Atypical antipsychotics: matching receptor profile to individual patient's clinical profile. CNS Spectr. 2004; 9(10 Suppl 11):6-14.

66. Correll CU, Manu P, Olshanskiy V, Napolitano B, Kane JM, Malhotra AK. Cardiometabolic risk of second-generation antipsychotic medications during first-time use in children and adolescents. JAMA. 2009;302(16):1765-1773.

67. Davies MA, Sheffler DJ, Roth BL. Aripiprazole: a novel atypical antipsychotic drug with a uniquely robust pharmacology. CNS Drug Rev. 2004;10(4):317-336.

68. American Psychiatric Association. Practice Guideline for the Treatment of Patients with Schizophrenia. 2nd ed. Arlington, VA: American Psychiatric Association; 2004.

69. Findling RL, Blumer JL, Kauffman R, et al. Pharmacokinetic effects of aripiprazole in children and adolescents with conduct disorder. Paper presented at: the XXIVth Collegium Internationale NeuroPsychopharmacologicum Congress; 20-24 June, 2004; Paris, France.

70. Abilify ${ }^{\circledR}$ [prescribing information]. Tokyo, Japan: Otsuka Pharmaceutical Co; 2013. Available from: http://www.otsuka-us.com/Documents/ Abilify.PI.pdf. Accessed August 19, 2014.

71. Curran MP. Aripiprazole in the treatment of irritability associated with autistic disorder in paediatric patients: profile report. CNS Drugs. 2011; 25(9):801-802.

72. Curran MP. Aripiprazole: in the treatment of irritability associated with autistic disorder in pediatric patients. Paediatr Drugs. 2011;13(3): 197-204.

73. Findling RL, Kauffman R, Sallee FR, et al. An open-label study of aripiprazole: pharmacokinetics, tolerability, and effectiveness in children and adolescents with conduct disorder. $J$ Child Adolesc Psychopharmacol. 2009;19(4):431-439.

74. Findling RL, Correll CU, Nyilas M, et al. Aripiprazole for the treatment of pediatric bipolar I disorder: a 30-week, randomized, placebocontrolled study. Bipolar Disord. 2013;15(2):138-149.

75. Mankoski R, Stockton G, Manos G, et al. Aripiprazole treatment of irritability associated with autistic disorder and the relationship between prior antipsychotic exposure, adverse events, and weight change. J Child Adolesc Psychopharmacol. 2013;23(8):572-576.

76. Youngstrom E, Zhao J, Mankoski R, et al. Clinical significance of treatment effects with aripiprazole versus placebo in a study of manic or mixed episodes associated with pediatric bipolar I disorder. J Child Adolesc Psychopharmacol. 2013;23(2):72-79.

77. Tramontina S, Zeni CP, Ketzer CR, Pheula GF, Narvaez J, Rohde LA. Aripiprazole in children and adolescents with bipolar disorder comorbid with attention-deficit/hyperactivity disorder: a pilot randomized clinical trial. J Clin Psychiatry. 2009;70(5):756-764.

78. Uttley L, Kearns B, Ren S, Stevenson M. Aripiprazole for the treatment and prevention of acute manic and mixed episodes in bipolar I disorder in children and adolescents: a NICE single technology appraisal. Pharmacoeconomics. 2013;31(11):981-990. 
79. Geller B, Luby JL, Joshi P, et al. A randomized controlled trial of risperidone, lithium, or divalproex sodium for initial treatment of bipolar I disorder, manic or mixed phase, in children and adolescents. Arch Gen Psychiatry. 2012;69(5):515-528.

80. Barzman DH, DelBello MP, Kowatch RA, et al. The effectiveness and tolerability of aripiprazole for pediatric bipolar disorders: a retrospective chart review. J Child Adolesc Psychopharmacol. 2004;14(4): 593-600.

81. Biederman J, McDonnell MA, Wozniak J, et al. Aripiprazole in the treatment of pediatric bipolar disorder: a systematic chart review. CNS Spectr. 2005;10(2):141-148.

82. Fraguas D, Correll CU, Merchán-Naranjo J, et al. Efficacy and safety of second-generation antipsychotics in children and adolescents with psychotic and bipolar spectrum disorders: comprehensive review of prospective head-to-head and placebo-controlled comparisons. Eur Neuropsychopharmacol. 2011;21(8):621-645.

83. Fleischhaker C, Heiser P, Hennighausen K, et al. Weight gain in children and adolescents during 45 weeks treatment with clozapine, olanzapine and risperidone. J Neural Transm. 2008;115(11):1599-1608.

84. Martínez-Ortega JM, Diaz-Atienza F, Gutiérrez-Rojas L, Jurado D, Gurpegui M. Confounding by indication of a specific antipsychotic and the increase of body mass index among children and adolescents. Eur Child Adolesc Psychiatry. 2011;20(11-12):597-598.
85. Findling RL, Mankoski R, Timko K, et al. A randomized controlled trial investigating the safety and efficacy of aripiprazole in the long-term maintenance treatment of pediatric patients with irritability associated with autistic disorder. J Clin Psychiatry. 2014;75(1):22-30.

86. Findling RL, Robb A, Nyilas M, et al. A multiple-center, randomized, double-blind, placebo-controlled study of oral aripiprazole for treatment of adolescents with schizophrenia. Am J Psychiatry. 2008;165(11):1432-1441.

87. Safer DJ, Calarge CA, Safer AM. Prolactin serum concentrations during aripiprazole treatment in youth. J Child Adolesc Psychopharmacol. 2013;23(4):282-289.

88. Ho JG, Caldwell RL, McDougle CJ, et al. The effects of aripiprazole on electrocardiography in children with pervasive developmental disorders. J Child Adolesc Psychopharmacol. 2012;22(4):277-283.

89. Germanò E, Italiano D, Lamberti M, et al. ECG parameters in children and adolescents treated with aripiprazole and risperidone. Prog Neuropsychopharmacol Biol Psychiatry. 2014;51:23-27.
Adolescent Health, Medicine and Therapeutics

\section{Publish your work in this journal}

Adolescent Health, Medicine and Therapeutics is an international, peer-reviewed, open access journal focusing on health, pathology, and treatment issues specific to the adolescent age group. All aspects of health maintenance, preventative measures and disease treatmen interventions are addressed within the journal and practitioners from

\section{Dovepress}

all disciplines are invited to submit their work as well as healthcare researchers and patient support groups.. The manuscript management system is completely online and includes a very quick and fair peerreview system. Visit http://www.dovepress.com/testimonials.php to read real quotes from published authors.

Submit your manuscript here: http://www.dovepress.com/adolescent-health-medicine-and-therapeutics-journal 